\title{
Decomposing the Effect of Population Ageing on Labour Supply
}

\author{
By Johann Fuchs*
}

\begin{abstract}
Current demographic analyses suggest that Germany's workforce will both age and shrink in the coming decades. This paper provides a decomposition of the projected change in the overall labour force into a population and a participation component. Using a scenariobased approach, the analysis was enlarged by deriving a migration effect and a pure ageing effect from the population component. Furthermore, the interaction between population structure and labour participation was evaluated in more detail. An important result is that the most reliable factor of any labour force forecast, the current age structure of the population, will have a strong effect on the size of the future labour force. Furthermore, the effect of increasing labour participation rates will be significantly offset by the negative population trend. In Germany, domestic labour reserves will not be able to compensate the demographically related loss of workers.
\end{abstract}

\section{Introduction}

There is presumably a general agreement that the ageing of the population will affect size and structure of the labour supply (e.g. Tossi 2012). According to the most up-to-date projection of the Federal Statistical Office, Germany's population will probably shrink and, maybe more importantly, the share of older individuals will become larger (Federal Statistical Office 2009). In most European countries the situation is similar (Carone 2005).

An ageing population could have dramatic implications on various areas of society. One important outcome of the ageing process is a decreasing number of people of working age. As a consequence, forecasts show a substantially decreasing and ageing labour force in Germany. There are already fears today that Germany may be faced with a shortage of labour, especially of skilled workers, which raises the question about the path of the future production potential of the economy in an ageing society (e.g. European Central Bank 2011).

The supply of labour develops as a result of changes in its factors "natural population change" (births and deaths), migration and labour force participation. The degree to which these components can be predicted differs. The trends in fertility and mortality in particular are fairly stable and their

"Senior Researcher, Institute for Employment Research, Germany. 
labour market effects can be estimated long in advance. In the case of labour force behaviour, it is at least possible to draw an upper limit for the labour participation rate, whereas the number of migrants is hard to predict.

In demography there are approaches which are used to trace back the development of the population or other quantities, e.g. demographic rates, to the factors that are behind them (e.g. Das Gupta 1978). Similar decompositions are found in the context of labour supply projections. The changes in the supply of labour are typically broken down into the factors "population changes" and "changes in the activity rates" (e.g. Ellison, Tinsley and Houstan 1997).

The decomposition approach implies an interaction effect between changes in population structure and activity rates ${ }^{1}$. This effect was often neglected in literature (e.g. Madouros 2006). In the case of Germany, however, the results presented here indicate an important magnitude of the interaction effect. An analysis of the interaction term helps to have a closer look at the impact of rising labour participation in case of an ageing population.

The population effect is the result of fertility, mortality and migration. The decomposition into two components (plus interaction effect) might be insufficient for countries with strong migration movements. In order to quantify the impact of migration, this study takes a scenario-based method, which Dinkel and Meinl (1991) developed to decompose the population development, and applied it to the projected changes in labour supply. Bijak et al (2007) performed a similar approach by some sensitivity analyses, but only considered the effects of different fertility rates and labour participation rates.

In this paper, the change of the population component is broken down into further components. The first, called the "demographic component", shows the effects of fertility, mortality and the changing age structure of the population. The second effect is the migration component. This part deals with the net inflow of migrants, but includes their reproductive behaviour as well.

As labour participation rates are age-specific, an ageing population should have a negative outcome on size and structure of the labour force. This effect can be calculated by keeping the age structure of the population constant. An estimate for the impact of population ageing on the labour force will be derived by comparing an "age structure" scenario to the purely demographic variant. The results underline the outstanding importance of the current age structure of the population for the labour force.

The paper is structured as follows: The following section describes the data for the empirical analysis. A brief overview of the development of the German labour supply until 2050, including population and labour participation trends, is embedded. The third section explains the model used for the decomposition. The results are presented in section 4. It starts with comparing the main components demography, participation and migration, followed by results for the disentangling of the demographic component due to the ageing

\footnotetext{
${ }^{1}$ The terms "labour force participation rate", "labour participation rate" and "activity rate" are used interchangeably in this paper.
} 
influence. Next, the interaction effect is more closely analysed. The summary looks into the consequences for labour market policy.

\section{The Data: An Overview to Population and Labour Force Trends in Germany}

The data for this article were provided by the Institute for Employment Research (Institut für Arbeitsmarkt- und Berufsforschung, IAB). The IAB labour force projections are based on estimations of the long-term trends of population growth and labour participation rates (see also the Annex). The most important features of the developments are summarized in the following.

\section{Population}

Germany is experiencing considerable population ageing, which is expected to speed up within the next few years. ${ }^{1}$ That means that fewer young and more elderly persons than today are expected to live in Germany. This trend is attributable only to fertility, as low birth rates determine the current age structure, which is most important for the future path of population development. The baby boom of the mid-50s and 60s ended abruptly with a sharp decline in birth rates in the early 70s. The birth rates even fell to subreplacement level in 1971. Since then, birth rates have been year after year far below the value necessary to keep population constant in the long run. Total fertility rate is currently about 1.4 children per woman. The population scenarios in use assume that fertility will remain stable at this level.

Mortality fell considerably in the past. Especially the mortality of elderly people has significantly decreased for the last 20 years, whereas the death risk of infants and children has only improved to a smaller degree, because mortality of the younger had already reached a very low point. It is expected that life expectancy will still increase, but this improvement will affect the elderly more than the younger. Mortality does not, however, have a major impact on the working population.

For the German population, international migration has been of primary significance. In the past fifty years, net migration amounted to an average of approx. 190,000 persons per annum. In the present paper, an annual net migration of 200,000 persons is assumed. In addition, there is also a variant which does not take migration into account at all.

The baby-boom generation has grown up and dominates the large group of prime-age workers these days. In the coming 10 to 20 years, the labour force in Germany will be heavily affected by the ageing of the baby-boom cohorts. After 2020, the baby-boomers will start to change from the labour market into the retirement system. Around 2030, the baby-boomers will mark the peak in the number of the older workers (Figure 1). As a consequence, the working population in Germany will age considerably and will shrink more strongly

\footnotetext{
${ }^{1}$ For the population data see Federal Statistical Office ( 2009).
} 
than the total population. This development will be most important for the future labour force.

Figure 1. Population Aged 0-79, Single Years of Age, 2010, 2030 and 2050

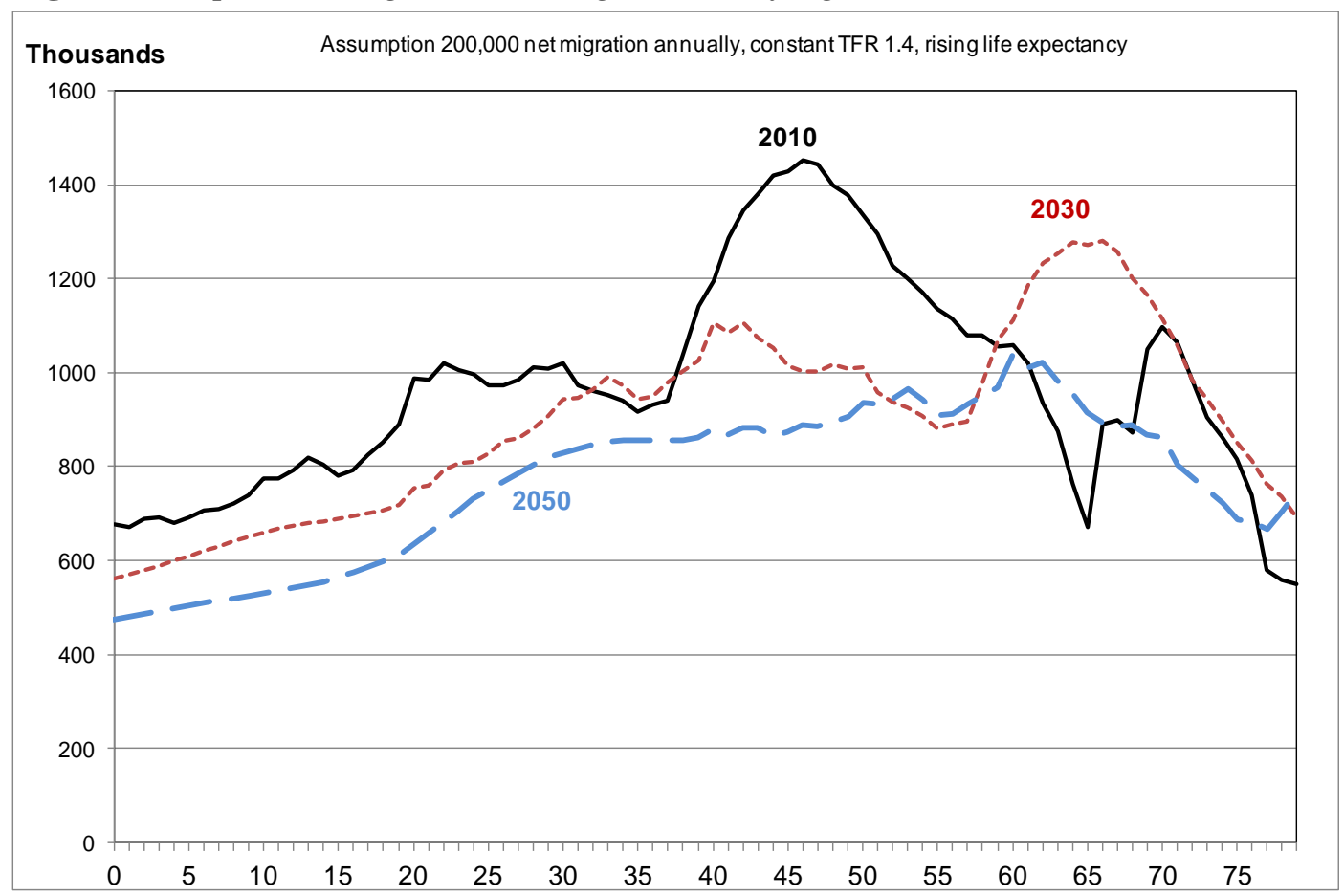

Sources: Federal Statistical Office (2009).

\section{Labour Participation Rates}

The participation rates in use stem from the latest IAB projection. Labour participation is based on the current definition of the International Labour Organization (ILO), but they take into account an estimate for the "hidden labour force". ${ }^{1}$

Since the early 1970s, labour participation of women has been increasing in Germany. Figures 2 and 3 show the age-specific labour participation rates since the German reunification in 1990. Participation of prime-aged women is rather high, even in a European context (see Carone 2005). Although the participation rates for females are projected to continue to rise, the results indicate that the age-specific labour participation rates for men will remain higher than those for women (see Figure 2 and 3).

Discouraging early retirement has already had positive effects on the labour participation rates of the elderly. Furthermore, from 2011 onwards, the legal retirement age is scheduled to increase stepwise. That is why for both sexes a significant rise in the labour participation of older workers can be expected.

\footnotetext{
${ }^{1}$ The labour force covers all employed and unemployed persons. The labour force participation rate relates the labour force to the population. The hidden labour force (hidden unemployment, discouraged workers) includes those people who are willing to work in principle but for various reasons no longer appear in official statistics when the labour market situation is poor.
} 
In contrast, the participation rate of the younger is projected to decrease, which is in line with educational trends, assuming an inverse relationship between labour participation and enrolment in education (see Clark 2011).

Figure 2. Age-Specific Labour Participation Rates, Females

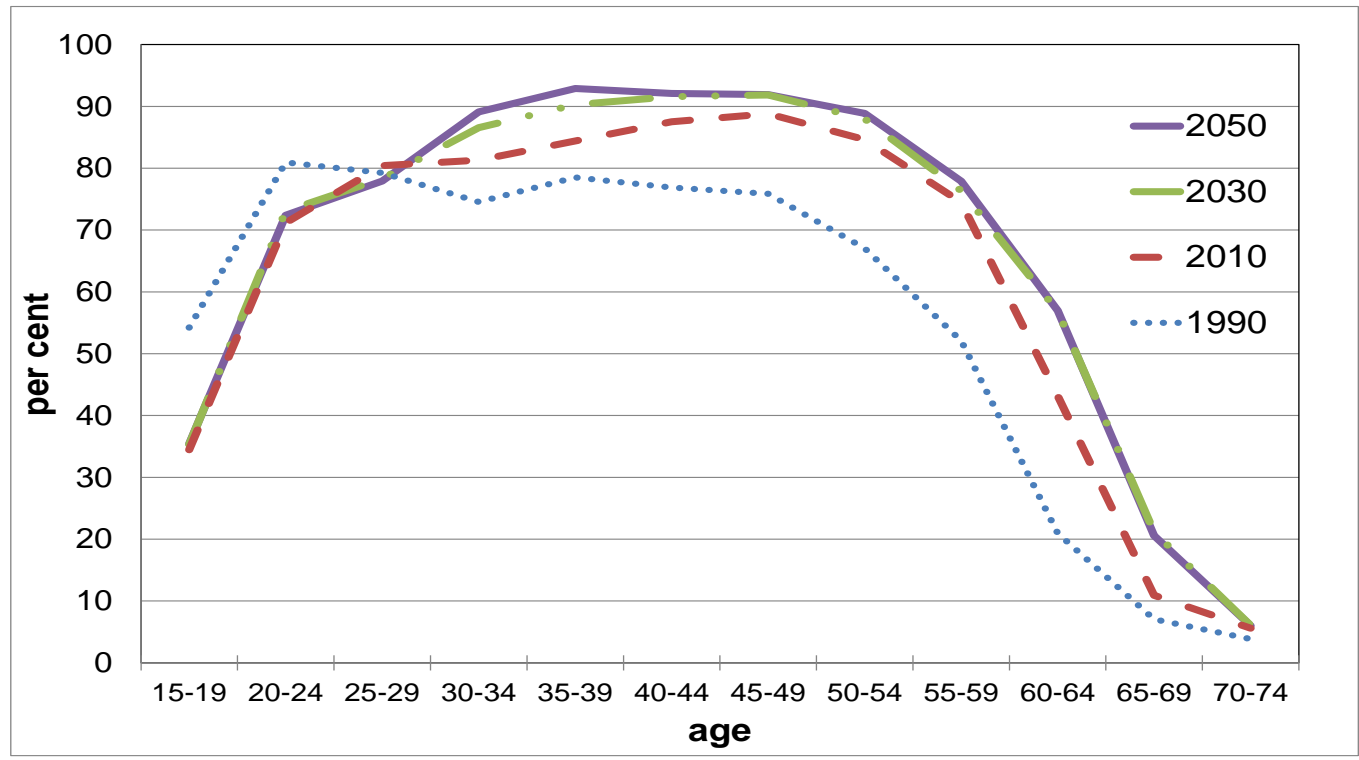

Source: IAB data base (see Annex).

Figure 3. Age-Specific Labour Participation Rates, Males

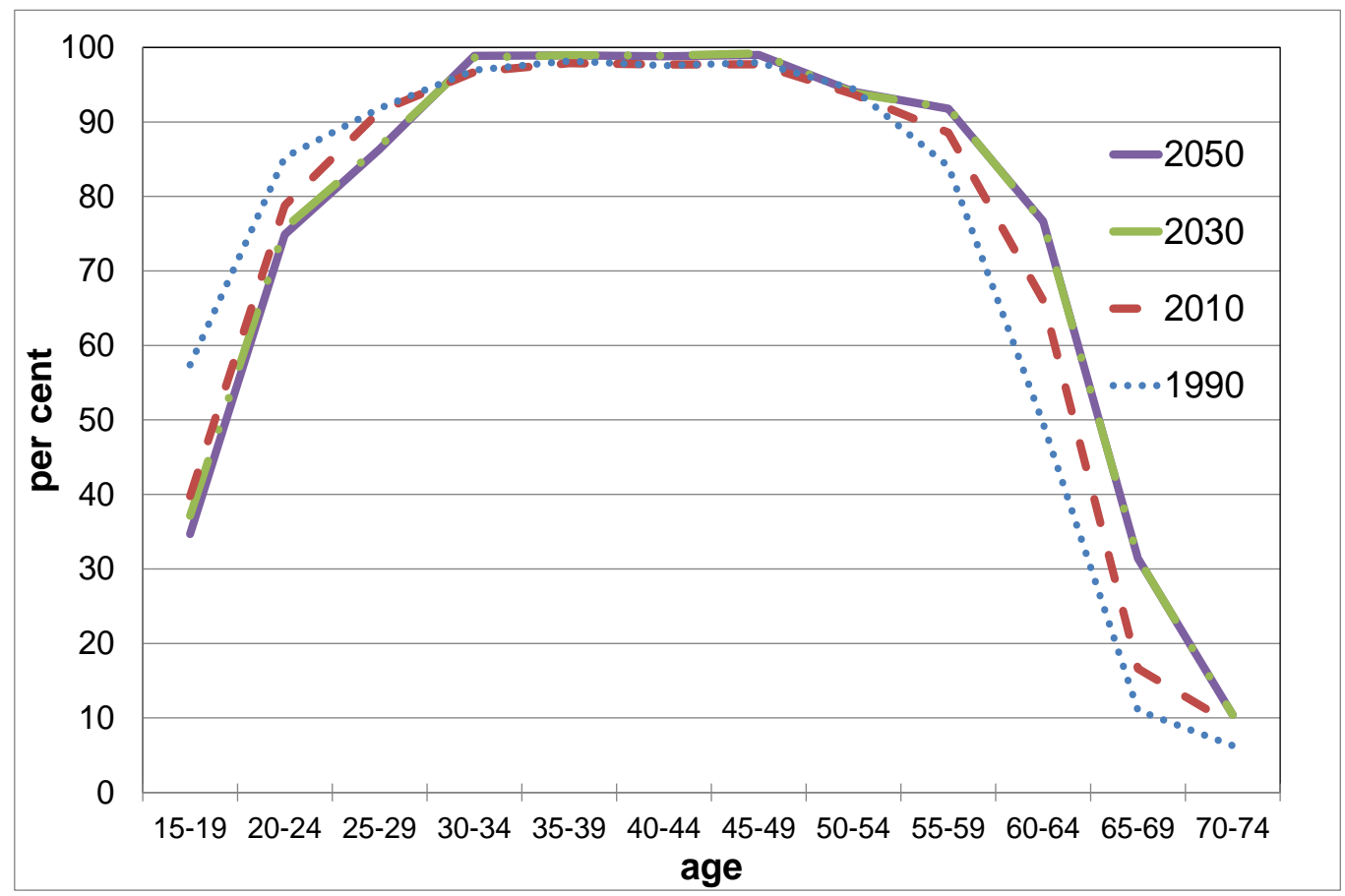

Source: IAB data base (see Annex). 


\section{Labour Force Scenarios}

This section briefly describes three scenarios which differ in respect to migration and participation assumptions (see Figure 4).

When labour participation rates are held constant and no immigration is taken into account, the development of the labour force will only be driven by natural population movement (birth/death) and the ageing of the workforce. This scenario therefore shows the overall demographic influence (Scenario S1). From Figure 4, a dramatic reduction of the labour force is apparent.

In case of no immigration but increasing participation rates of women and older workers, the negative population trend would be dampened a little (Scenario S2). Nevertheless, only 29.4 million workers are left towards the end of the projection horizon of Scenario 2.

Given an annual net migration of 200,000 immigrants and rising labour participation, the overall labour force will remain almost stable until 2015 (Scenario S3). After 2015, the projection shows a slightly decreasing labour force, but the trend is clearly speeding up.

Figure 4. Alternative Labour Force Scenarios, 1990 to 2050

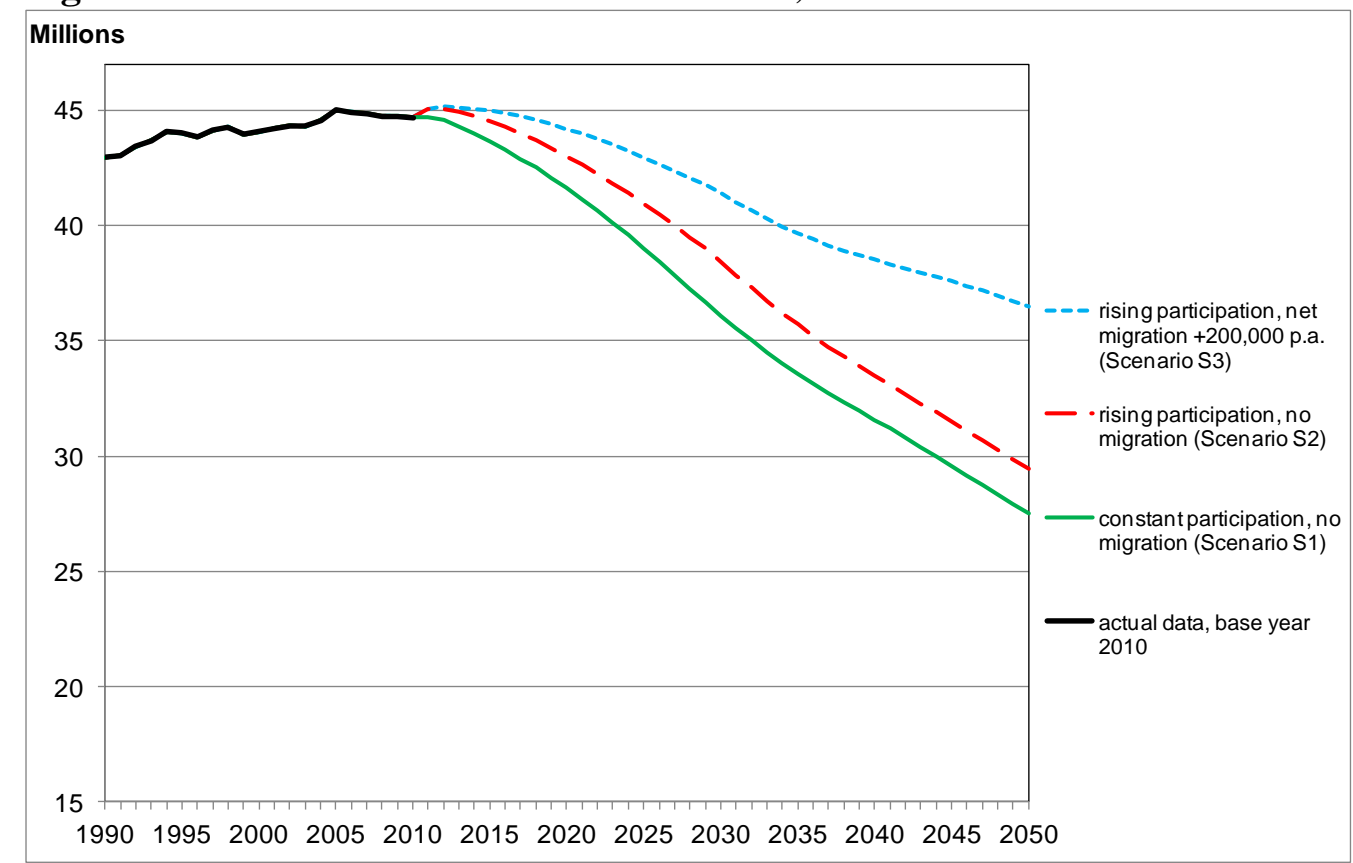

Source: IAB data base (see Annex).

\section{Decomposing Labour Force Growth}

The overall change in labour supply can be split into different components. In general, the influence of the components is not to be understood as a causal influence. There are factors which are "behind" the components and determine them. For example, labour force participation depends on basic social conditions, on the labour market situation, on wages, etc. (see Mulligan and 
Molin 2004). However, an examination of these causal chains would be out of the scope of the following analysis.

\section{An Analytical Decomposition Model}

The total labour force $L_{t}$ is divided into $i$ groups, e.g. by age and sex. Let $\mathrm{L}_{\mathrm{xt}}$ be the labour force at time $\mathrm{t}$ for group $\mathrm{x}$. Let $\mathrm{a}_{\mathrm{xt}}$ be the group-specific labour participation rate and $\mathrm{P}_{\mathrm{xt}}$ the population of group $\mathrm{x}$. The total labour force at time $\mathrm{t}$ is given by summing over the subscript $\mathrm{x}$.

(1) $L_{t}=\sum L_{x t}=\sum_{x} a_{x t} P_{x t} \quad$ where $x=1,2, \ldots i$

Applying a simple decomposition analysis, the change in the labour force $\left(\Delta \mathrm{L}_{\mathrm{t}}\right)$ between a year $\mathrm{t}$ and the base year $(\mathrm{t}=0)$ can be decomposed as follows:

$$
\Delta L_{t}=\sum_{x}\left\{\left[a_{x 0}\left(P_{x t}-P_{x 0}\right)\right]+\left[\left(a_{x t}-a_{x 0}\right) P_{x 0}\right]+\left[\left(a_{x t}-a_{x 0}\right)\left(P_{x t}-P_{x 0}\right)\right]\right\}
$$

For convenience of representation, let at be a $1 \mathrm{x}$ i row vector of groupspecific participation rates $\left(\mathrm{a}_{1 \mathrm{t}} \ldots \mathrm{a}_{\mathrm{xt}} \ldots \mathrm{a}_{\mathrm{it}}\right)$ in period $\mathrm{t}$, and $\mathrm{P}_{\mathrm{t}}$ a $\mathrm{i}$ x 1 column vector $\left(\mathrm{P}_{1 \mathrm{t}} \ldots \mathrm{P}_{\mathrm{xt}} \ldots . \mathrm{P}_{\mathrm{it}}\right)$ whose elements represent the number of people in group $\mathrm{x}$ in period $\mathrm{t}$.

The first term $\left[\mathrm{a}_{0}\left(\mathrm{P}_{\mathrm{t}}-\mathrm{P}_{0}\right)\right]$ of (2) shows the population effect due to changes in size and structure of the population when age-specific participation rates remain constant (base year $t=0$ ). The total population effect at time $t$ is calculated by summing the effects over all groups.

\section{(3) Population component: $\quad a_{0}\left(P_{t}-P_{0}\right)=a_{0} P_{t}-a_{0} P_{0}$}

The second part of $\left.(2),\left[\left(a_{t}-a_{0}\right) P_{0}\right)\right]$, is the participation rate effect due to changes in the age-specific participation rates, given the population from the base year $\mathrm{t}=0$ of the projection. The total participation effect is again obtained by summing the effects over all groups.

(4) Participation component: $\quad\left(a_{t}-a_{0}\right) P_{0}=a_{t} P_{0}-a_{0} P_{0}$

The third part of (2) represents a second order change. This is the interaction effect from the simultaneous change in population and labour participation rates (see below).

\section{Decomposing the Population Effect}

The population component (3) includes the effect of migration on population and thus on labour supply. When migration is important for the population development, one might be interested to quantify its impact. If one simply subtracts total net migration, this would, however, lead to an underestimation of the secondary migration effect which results from the immigrants' generative behaviour (births, deaths). Furthermore, the total net migration figure, summed up over a time span, does not account for the ageing of the immigrants.

In order to disentangle migration and natural population effects, an approach is adopted that Dinkel and Meinl (1991) employed for decomposing 
the demographic factors of the population development. They extrapolated a given initial population under various assumptions with regard to mortality, birth trends and migration. This yields different variants for the future population. From the differences in these variants, one can simply derive the sought-after effects.

This method is applied to the projected labour force in this paper. We use this flexible, scenario-based approach to generate estimates for the migration effect and the impact of ageing on labour supply (see Bijak et al 2007). The following derivation refers on the labour force scenarios illustrated in Figure 4.

- Scenario $\mathrm{S} 1\left(=\mathrm{a}_{0} \mathrm{P}_{\mathrm{t}}^{\mathrm{h}}\right)$ is based on constant labour participation rates (base year 2010: $\mathrm{t}=0$, so $\mathrm{a}_{0}=\mathrm{a}_{2010}$ ). The population is denoted $\mathrm{P}_{\mathrm{t}}^{\mathrm{h}}$, as it projects the "home" population, i.e. migration is not taken into account.

- In Scenario $\mathrm{S} 2\left(=\mathrm{a}_{\mathrm{t}} \mathrm{P}_{\mathrm{t}}^{\mathrm{h}}\right)$, the population is extrapolated in the same way as in S1 without migration, but the age- and sexspecific labour participation rates are no longer held constant $\left(a_{t}\right)$.

- Scenario $S 3\left(=a_{t} P_{t}\right)$ includes migration movements. Therefore the population is denoted $\mathrm{P}_{\mathrm{t}}$. Note that $\mathrm{P}_{0}=\mathrm{P}_{0}^{\mathrm{h}}$.

\section{Demographic Component without the Influence of Migration}

The pure demographic development effect ${ }^{1}$, without any migration influence and any change in labour participation, is given by the change in Scenario S1; in other words, the demographic effect equals the difference in the labour force of S1 between two points in time. In the German case, the demographic effect is negative.

$$
\text { Pure demographic }
$$

effect:

$$
\Delta S 1_{t}=S 1_{t}-S 1_{0}=a_{0} P_{t}^{h}-a_{0} P_{0}^{h}=a_{0}\left(P_{t}^{h}-P_{0}^{h}\right)
$$

\section{Migration Component}

An estimate of the migration impact can be derived by means of a simple comparison of two scenarios, both based on identical assumptions in respect to fertility, mortality and labour participation. In order to calculate the migration component, a labour force scenario that includes future migration (Scenario S3) is compared to one, which excludes migration flows (Scenario S2). In Figure 4, the area between S3 and S2 gives the migration effect.

$$
\text { (6) Migration effect: } \quad S 3_{t}-S 2_{t}=a_{t} P_{t}-a_{t} P_{t}^{h}=a_{t}\left(P_{t}-P_{t}^{h}\right)
$$

The migration effect includes the generative consequences of migration; i.e. the births and deaths of immigrants. It also covers the effect of the age structure of net migration on the labour force, because the immigrated population is zero at the beginning of the observation period $(t=0)$.

\footnotetext{
${ }^{1}$ In the terminology of demography, the demographic component often includes migration. For simplification, the term "demographic component" refers in this text only to population change without migration.
} 
The migration effect is determined on the basis of immigrants' increasing labour participation. Therefore, the migration effect implicitly contains an interaction effect from a change in behaviour and migration. It appears to make sense to assign this combined effect to the migration component, because the higher labour participation rates only yield an additional labour force when interacting with migration. ${ }^{1}$

\section{Ageing Effect}

The demographic component comprises the effect of an ageing population on labour supply. Due to age-specific labour participation rates, an ageing population could have a negative impact on the size (and structure) of the labour force. In order to quantify this effect, a labour force scenario (S1k) was calculated that keeps the age structure of the population constant, that is, the age structure from a base year $t=0$ was used for weighting.

A constant age structure is obtained by applying the age structure of the base year to the projected total population. The population is of the size projected for year $\mathrm{t}$ but has the age structure from the base year.

The impact of changes in the composition according to gender was not modelled here. So this age composition is kept constant separately for both sexes.

For each sex g equation (7) is calculated, where $\mathrm{j}=$ age group, $\mathrm{g}=\{$ males, females .

$$
S 1 k_{g t}=\sum_{j}\left[a_{g j 0} P_{g j t}^{\text {const } a g \theta_{i} h}\right]=\sum_{j}\left[a_{g j 0} \frac{P_{g j 0}}{\sum_{j} P_{g j 0}} \sum_{j} P_{g j t}^{h}\right]
$$

$\mathrm{P}_{g j 0} / \sum_{j} P_{g j 0}$ is the proportion of age group $\mathrm{j}$ in the total population of the same sex at time $\mathrm{t}=0$. Weighting by the projected corresponding population for the scenario without migration, $\sum_{j} P_{g j t}^{h}$, results in a population, $\mathrm{P}_{\mathrm{gjt}}^{\text {const age, } \mathrm{h}}$, at time $\mathrm{t}$ with a constant age structure from $\mathrm{t}=0$.

Summation over both sexes gives $S 1 k_{t}=\Sigma_{g} S 1 k_{g t}$.

Scenario S1k is based on S1. The difference between Scenario S1k and the scenario with a changing population structure (S1) yields the age-structure effect. It is a result of age-dependent labour force participation - which remains constant - and the shift in the age structure of the population. The effect is understood as part of the overall demographic effect, because it mainly reflects earlier generative processes. ${ }^{2}$

$$
\text { Ageing effect }=S 1 k_{t}-S 1_{t} \text {, where } S 1_{t}=a_{0} P_{t}^{h}
$$

\footnotetext{
${ }^{1}$ In order to work out a migration effect without a change in behaviour, the migration variants can be computed on the basis of constant labour participation rates. The interaction effect between migration and participation can be inferred from that. This effect is only referred to here in order to complete the picture. It will not be examined in any further detail.

${ }^{2}$ The current age structure also covers previous migration events. Seen from $t=0$, the ageing of those who immigrated earlier contributes to the age-structure effect.
} 


\section{The Participation Component and the Interaction Term}

The effect of changing age-specific labour participation rates on the labour force potential is specified in equation (2) with the term $\left.\left[\left(a_{t}-a_{0}\right) P_{0}\right)\right]$. The change in behaviour is weighted according to the decomposition above using the population of the base year $\mathrm{t}=0$, so

$$
\left(a_{t}-a_{0}\right) P_{0}=a_{t} P_{0}-a_{0} P_{0}
$$

Combining the interaction effect with the participation effect (e.g. Ellison, Tinsley and Houston 1997) gives

$$
\left\{\left[\left(a_{t}-a_{0}\right) P_{0}\right]+\left[\left(a_{t}-a_{0}\right)\left(P_{t}-P_{0}\right)\right]\right\}=\left(a_{t}-a_{0}\right) P_{t}=a_{t} P_{t}-a_{0} P_{t}
$$

When migration is excluded, i.e. the "home" population which is taken as a basis is $\mathrm{P}_{\mathrm{t}}^{\mathrm{h}}$, the participation component equals the difference of the Scenarios S2 and S1:

(9) Labour participation effect, incl. interaction effect:

$S 2_{t}-S 1_{t}=a_{t} P_{t}^{h}-a_{0} P_{t}^{h}$

To sum up, this type of participation effect includes the interaction with the population change, but excludes any migration effects from base year $t=0$ onwards.

Note:

The overall change in the labour force potential between a year $t$ and the base year 0 is equal to the sum of the demographic effect, the participation effect (including the interaction effect from participation by age structure) and the migration effect, since

$\Delta L_{t}=\left(S 1_{t}-S 1_{0}\right)+\left(S 2_{t}-S 1_{t}\right)+\left(S 3_{t}-S 2_{t}\right)=S 3_{t}-S 1_{0}=a_{t} P_{t}-a_{0} P_{0}$

\section{Empirical Results}

Demographic, Participation and Migration Effect up to 2050

Table 1 summarizes the main components for different periods of time. What is clearly visible is the dominance of the demographic effect. For demographic reasons, Germany is expected to lose more than 17 million workers from 2010 to 2050.

Table 1. Components of Labour Force Change, 2010, 2030 and 2050 Thousands

\begin{tabular}{|c|c|c|c|c|}
\hline & Demography $^{\text {a) }}$ & Participation $^{\text {b) }}$ & Migration $^{\text {c) }}$ & Total \\
\hline $2010-2030$ & $-8,587$ & 2,340 & 2,957 & $-3,290$ \\
\hline $2030-2050$ & $-8,559$ & -429 & 4,105 & $-4,883$ \\
\hline $2010-2050$ & $-17,146$ & 1,912 & 7,062 & $-8,173$ \\
\hline
\end{tabular}

a) Includes the ageing effect.

b) Includes the interaction effect of demography and participation.

c) Assumes an annual net migration of ca. 200,000 persons and increasing participation rates.

Source: IAB data base, author's calculation. 
The additional supply of labour resulting from migration amounts to 7.1 million workers until 2050. Obviously, immigration at the assumed level cannot compensate for the demographic influence on the labour force by far.

The labour participation effect is even less pronounced and, surprisingly, it switches from positive to negative sign in the 2030-2050 period, which will be investigated below.

\section{The Ageing Effect}

Although age-specific labour participation rates were kept constant and migration was eliminated, the demographic component still covers population changes in size and age structure. By means of a comparison of Scenario S1 with S1k, based on a constant age structure of the population, we obtain the age-structure effect.

Scenario S1k shows, that if the age structure of population was kept constant, the labour force would decline by 11.8 million people from 2010 to 2050 (Figure 5).

Figure 5. Demographic Effect and Ageing, 1990 to 2050

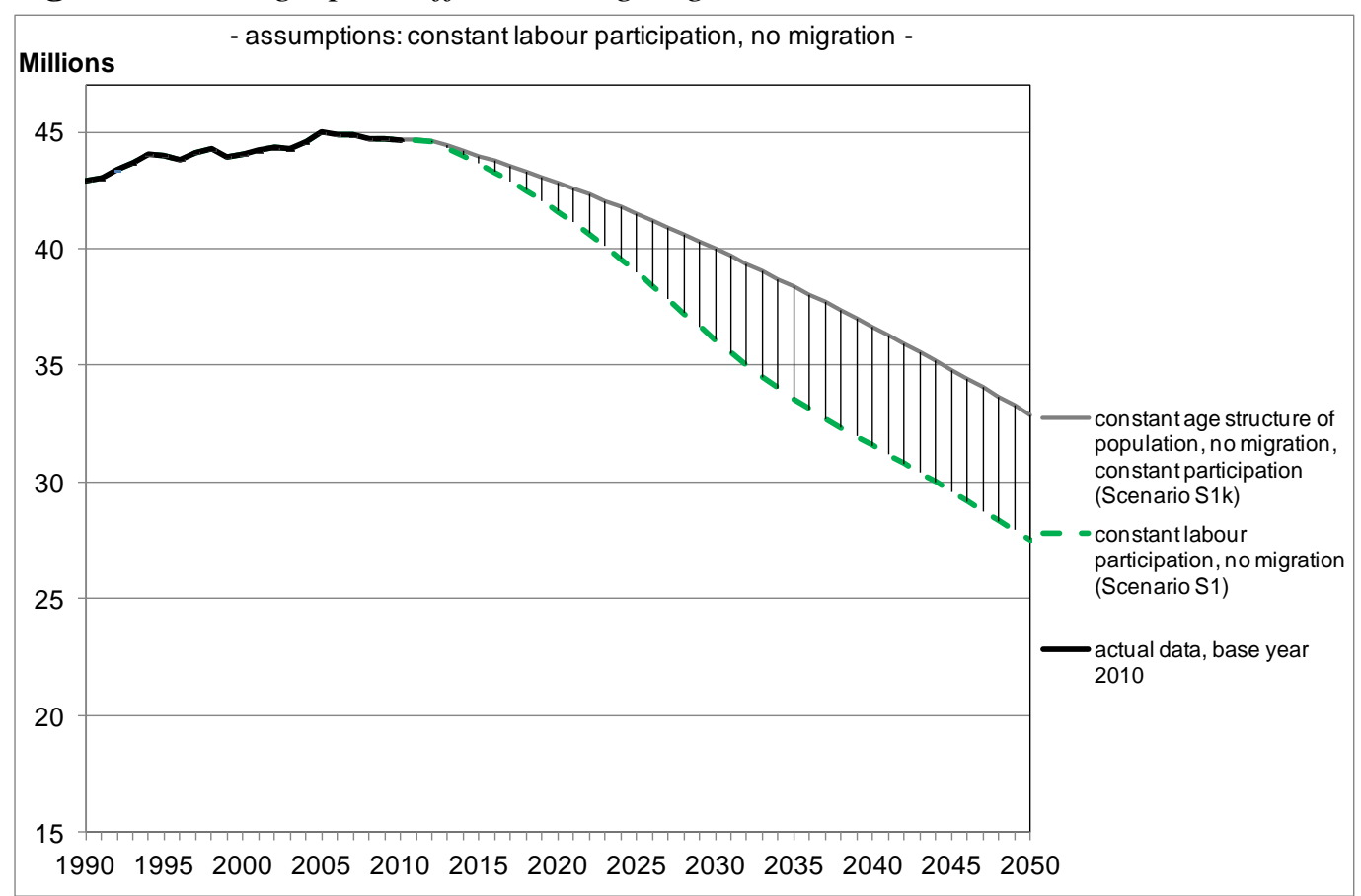

Source: IAB data base (see Annex), author's calculations.

Population ageing will obviously become more and more important (see hatched area in Figure 5) when the baby boomers are going to change from the prime-aged to the older-age group that has lower labour participation rates. The pure ageing component, derived as described, therefore amounts to 3.9 million from 2010 to 2030 and an extra 1.4 million in the period after that.

As expected, the ageing effect will stabilize when most of the baby boomers have retired after 2030 (view the hatched area). 
An important conclusion of this result is that a considerable part of the demographic impact is obviously already laid down in the age distribution of today's population.

\section{Labour Participation and the Interaction Effect}

It follows from Table 1 that the influence of the labour participation component on labour supply drops in the course of time. Between 2030 and 2050 , the participation component is actually negative, although the agespecific participation rates are rising. A comparison with the participation component, estimated with the base population, clarifies the reasons for that surprising development (see Table 2).

Table 2. Participation Component and Interaction Effect Thousands

\begin{tabular}{|l|l|l|l|}
\hline & $\begin{array}{l}\text { Participation } \\
\text { component including } \\
\text { interaction } \\
\left(\mathrm{a}_{\mathrm{t}}-\mathrm{a}_{0}\right) \mathrm{P}_{\mathrm{t}} \\
=\text { difference S2-S1 }\end{array}$ & $\begin{array}{l}\text { Participation } \\
\text { component* } \\
\left(\mathrm{a}_{\mathrm{t}}-\mathrm{a}_{0}\right) \mathrm{P}_{0} \\
=\text { change in Scenario } \\
\mathrm{S} 2 \mathrm{k}\end{array}$ & $\begin{array}{l}\text { Interaction } \\
\text { effect } \\
\left(\mathrm{a}_{\mathrm{t}}-\mathrm{a}_{0}\right) \\
\left(\mathrm{P}_{\mathrm{t}}-\mathrm{P}_{0}\right)\end{array}$ \\
\hline $2010-2030$ & 2,340 & 2,136 & 204 \\
\hline $2030-2050$ & -429 & 214 & -642 \\
\hline $2010-2050$ & 1,912 & 2,350 & -438 \\
\hline
\end{tabular}

* See Annex, Table A3, Scenario S2k

Source: Author's calculation.

Firstly, when participation rates are weighted with the population from 2010, there will be a positive, albeit smaller effect from 2030 onwards. It seems that rather high age-specific participation rates for the prime-aged will not allow much further gains after 2030 (see Annex, Table A2).

Secondly, the interaction effect, which arises from a negative population trend and a positive participation trend, amounts to some $-440,000$ people. Up to 2030, the interaction will be positive $(+204,000)$. Between 2030 und 2050, the interaction is about $-642,000$ workers. The ageing of the baby-boom generation implies that large groups with high labour participation rates will receive the lower age-specific participation rates from older workers. The outcome of this is a negative interaction effect from participation and population ageing. The negative effect happens although the participation rate of older workers is projected to rise.

\section{Conclusions}

This decomposition has shown the extent to which the most reliable factor, the demographic development, considered in isolation, will reduce the supply of labour. This demographic component was further disentangled by the size 
and the age structure of the population. It shows that an important part of the demographic influence is already given by the current age structure.

Higher labour participation rates can slow down the trend only slightly. As expected, the ageing of the baby-boom cohorts has an additional adverse effect on the overall labour force, which can be deduced from the interaction effect. It should be realised that the effect of any rise in the participation rates will be partly offset by population ageing.

In conclusion, domestic labour reserves will not be able to compensate the demographically related loss of workers in Germany. This is a crucial prospect in respect to the future production potential. Therefore, population ageing will most probably lower the potential growth rate of the economy.

A stronger counteraction to the demographic influence would result from migration. However, even with a quite high net immigration of some 200,000 people per year, the downward trend in the labour supply of Germany can no longer be halted in the foreseeable future. From the viewpoint of the labour market, qualified workers in particular would be necessary - but they are also in demand in other countries. This impedes the possibilities of German immigration policy to a considerable extent. ${ }^{1}$

The analysis was restricted to a pure per-capita examination. In actual fact, however, the relevance of working hours should be considered as well, since longer annual working hours counteract the person-related effect. . Further research is intended to examine whether there are possibilities for any enlargement in the working time and to which extend this could compensate for the decreasing labour force in terms of hours (labour volume).

\section{References}

Carone, G., 2005. Long-term labour force projections for the 25 EU Member States: A set of data for assessing the economic impact of ageing. Economic Papers (European Economy, European Commission, Directorate-General for Economic and Financial Affairs) 235.

Clark, D., 2011. Do Recessions Keep Students in School? The impact of youth unemployment on enrolment in post-compulsory education in England. Economica 78, pp. 523-545.

Das Gupta, P., 1978. A general method of decomposing a difference between two rates into several components. Demography 15(1), pp. 99-112.

Dinkel, R. H. and Meinl, E., 1991. Die Komponenten der Bevölkerungsentwicklung in der Bundesrepublik Deutschland und der DDR zwischen 1950 und 1987. Zeitschrift für Bevölkerungswissenschaft 17(2), pp. 115-134. (German version only).

European Central Bank, 2011. Trends in potential output. Monthly Bulletin (Jan 2011).

${ }^{1}$ Furthermore, most of the top ten source countries of immigrants who arrived in Germany in 2013 face a fundamental demographic problem themselves (see Kurkó 2010 for Romania). 
Vol. 2, No. 2 Fuchs: Decomposing the Effect of Population Ageing on Labour Supply

Ellison, R., Tinsley, K. and Houston, N., 1997. British labour force projections: 19972006. Labour Market Trends (Feb 1997), pp. 51-67.

Federal Statistical Office, 2009. Germany's Population by 2060. Results of the 12th coordinated population projection. Wiesbaden. Available at < https://www.destatis.de/EN/Publications/Specialized/Population/GermanyPopulat ion2060.pdf? blob=publicationFile $>$.

Kurkó, I., 2010. The Influcence of Demographic Aging on the Potential Labour Market Supply. Journal of Settlements and Spatial Planning 1(2), pp. 117-124.

Madouros, V., 2006. Projections of the UK labour force, 2006 to 2020. Labour Market Trends (Jan 2006), pp. 13-27.

Mulligan, G. F. and Molin, A., 2004. Estimating population change with a twocategory shift-share model. Ann Reg Sci 38, pp. 113-130.

Tossi, M., 2012. Labor force projections to 2020: a more slowly growing workforce. Monthly Labor Review (Jan 2012), pp. 43-64. 


\section{Annex}

Data from the IAB data base are available upon request.

Table A1. Population by Age and Sex, 2010, 2030, 2050

Thousands

\begin{tabular}{|l|l|l|l|l|l|l|l|l|l|l|l|l|l|l|l|}
\hline & $\mathbf{0 - 1 4}$ & $\begin{array}{l}\mathbf{1 5 -} \\
\mathbf{1 9}\end{array}$ & $\begin{array}{l}\mathbf{2 0 -} \\
\mathbf{2 4}\end{array}$ & $\begin{array}{l}\mathbf{2 5 -} \\
\mathbf{2 9}\end{array}$ & $\begin{array}{l}\mathbf{3 0 -} \\
\mathbf{3 4}\end{array}$ & $\begin{array}{l}\mathbf{3 5 -} \\
\mathbf{3 9}\end{array}$ & $\begin{array}{l}\mathbf{4 0 -} \\
\mathbf{4 4}\end{array}$ & $\begin{array}{l}\mathbf{4 5 -} \\
\mathbf{4 9}\end{array}$ & $\begin{array}{l}\mathbf{5 0 -} \\
\mathbf{5 4}\end{array}$ & $\begin{array}{l}\mathbf{5 5}- \\
\mathbf{5 9}\end{array}$ & $\begin{array}{l}\mathbf{6 0 -} \\
\mathbf{6 4}\end{array}$ & $\begin{array}{l}\mathbf{6 5 -} \\
\mathbf{6 9}\end{array}$ & $\begin{array}{l}\mathbf{7 0 -} \\
\mathbf{7 4}\end{array}$ & $\mathbf{7 5 +}$ & total \\
\hline males & & & & & & & & & & & & & & & \\
\hline 2010 & 5,633 & 2,169 & 2,535 & 2,519 & 2,423 & 2,589 & 3,447 & 3,598 & 3,100 & 2,693 & 2,202 & 2,226 & 2,231 & 2,744 & 40,108 \\
\hline 2030 & 4,888 & 1,829 & 2,045 & 2,285 & 2,505 & 2,569 & 2,726 & 2,505 & 2,299 & 2,376 & 3,036 & 2,963 & 2,285 & 3,772 & 38,082 \\
\hline 2050 & 4,000 & 1,537 & 1,798 & 2,081 & 2,229 & 2,245 & 2,262 & 2,288 & 2,381 & 2,370 & 2,419 & 2,091 & 1,754 & 4,837 & 34,291 \\
\hline females & & & & & & & & & & & & & & & \\
\hline 2010 & 5,349 & 2,060 & 2,431 & 2,446 & 2,364 & 2,517 & 3,299 & 3,462 & 3,042 & 2,751 & 2,277 & 2,405 & 2,597 & 4,670 & 41,669 \\
\hline 2030 & 4,581 & 1,694 & 1,881 & 2,085 & 2,303 & 2,413 & 2,653 & 2,541 & 2,385 & 2,469 & 3,138 & 3,179 & 2,644 & 5,514 & 39,481 \\
\hline 2050 & 3,743 & 1,416 & 1,634 & 1,865 & 2,005 & 2,053 & 2,116 & 2,194 & 2,333 & 2,381 & 2,548 & 2,362 & 2,112 & 6,894 & 35,655 \\
\hline
\end{tabular}

Source: IAB data base.

Table A2. Labour Force Participation Rates by Age and Sex, 2010, 2030, 2050

Per cent

\begin{tabular}{|l|l|l|l|l|l|l|l|l|l|l|l|l|}
\hline & $\mathbf{1 5 - 1 9}$ & $\mathbf{2 0 - 2 4}$ & $\mathbf{2 5 - 2 9}$ & $\mathbf{3 0 - 3 4}$ & $\mathbf{3 5 - 3 9}$ & $\mathbf{4 0 - 4 4}$ & $\mathbf{4 5 - 4 9}$ & $\mathbf{5 0 - 5 4}$ & $\mathbf{5 5 - 5 9}$ & $\mathbf{6 0 - 6 4}$ & $\mathbf{6 5 - 6 9}$ & $\begin{array}{l}\mathbf{7 0 -} \\
\mathbf{7 4}\end{array}$ \\
\hline males & & & & & & & & & & & & \\
\hline 2010 & 39.8 & 78.8 & 91.5 & 96.7 & 97.9 & 97.7 & 97.7 & 93.7 & 88.6 & 66.1 & 16.6 & 9.1 \\
\hline 2030 & 37.1 & 75.8 & 86.7 & 98.6 & 99.0 & 98.9 & 99.2 & 93.9 & 91.9 & 76.5 & 31.4 & 10.4 \\
\hline 2050 & 34.7 & 74.9 & 86.3 & 98.9 & 98.9 & 98.8 & 99.0 & 94.1 & 91.8 & 76.7 & 31.4 & 10.4 \\
\hline females & & & & & & & & & & & & \\
\hline 2010 & 34.5 & 71.2 & 80.4 & 81.3 & 84.4 & 87.5 & 88.8 & 84.6 & 74.5 & 43.2 & 10.9 & 5.6 \\
\hline 2030 & 35.3 & 73.1 & 78.3 & 86.6 & 90.3 & 91.6 & 91.9 & 88.0 & 76.4 & 56.9 & 21.2 & 6.1 \\
\hline 2050 & 35.4 & 72.4 & 77.9 & 89.1 & 92.9 & 92.1 & 91.9 & 88.9 & 77.9 & 57.0 & 20.6 & 6.0 \\
\hline
\end{tabular}

Source: IAB data base. 
Vol. 2, No. 2 Fuchs: Decomposing the Effect of Population Ageing on Labour Supply

Table A3. Labour Force Scenarios for Selected Years

Thousands

\begin{tabular}{|c|c|c|c|c|c|}
\hline & \multicolumn{2}{|c|}{$\begin{array}{l}\text { Scenarios with constant } \\
\text { participation rates } \\
\text { (base year 2010) }\end{array}$} & \multicolumn{3}{|c|}{$\begin{array}{c}\text { Scenarios with rising age-specific } \\
\text { participation rates }\end{array}$} \\
\hline & $\begin{array}{l}\text { constant age } \\
\text { structure of } \\
\text { population (no } \\
\text { migration }^{1)} \text {, } \\
\text { constant } \\
\text { participation) } \\
\text { Scenario S1k }\end{array}$ & $\begin{array}{l}\text { no migration }^{1)} \\
\text { Scenario S1 }\end{array}$ & $\begin{array}{c}\text { constant } \\
\text { population (in } \\
\text { size and } \\
\text { structure) } \\
\text { Scenario S2k }\end{array}$ & $\begin{array}{l}\text { no migration }^{1)} \\
\text { Scenario S2 }\end{array}$ & $\begin{array}{c}\text { net migration } \\
+200,000 \\
\text { p,a, } \\
\text { Scenario S3 }\end{array}$ \\
\hline 1990 & 42,931 & 42,931 & 42,931 & 42,931 & 42,931 \\
\hline 2000 & 44,069 & 44,069 & 44,069 & 44,069 & 44,069 \\
\hline 2010 & 44,671 & 44,671 & 44,671 & 44,671 & 44,671 \\
\hline 2020 & 42,824 & 41,610 & 46,015 & 42,996 & 44,187 \\
\hline 2030 & 39,993 & 36,084 & 46,807 & 38,424 & 41,381 \\
\hline 2040 & 36,656 & 31,569 & 46,933 & 33,481 & 38,515 \\
\hline 2050 & 32,877 & 27,525 & 47,021 & 29,437 & 36,498 \\
\hline
\end{tabular}

1) No migration: These scenarios do not take into account any migration.

Source: IAB data base, author's calculations. 